\title{
Fundamental Considerations for Finite Element Modelling of Rubber Material Tensile Test
}

\author{
M. A. ABDULLAH \\ University of Debrecen, Faculty of Engineering, Department of Basic Technical Studies, m.ahmed@eng.unideb.hu \\ University of Debrecen
}

\section{Introduction}

Aim of this research is to get familiar with the fundamental considerations for finite element modelling of rubber's tensile test. Hyperelastic materials such as rubber are widely used in a variety of industries ranging from tire to aerospace for various structural applications. The most important feature of rubbers is their ability to experience substantial deformation under small loads and maintain initial configuration without noticeable permanent deformation after removal of the load.

They have a highly non-linear stress-strain behaviour and a simple elasticity module is no longer sufficient. Therefore, it is of great importance to characterize the elastic behaviour of highly extensible, nonlinear materials. [1]

Based on three strain invariants $I_{1}, I_{2}$ and $I_{3}$, the constitutive behaviour of hyperelastic material is derived from strain energy function (SEF) ' W.' It is the energy stored in the material by unit of reference volume (volume in the initial configuration) as a function of strain in the material at that point. [2]

$$
W=f\left(I_{1}, I_{2}, I_{3}\right)
$$

For which $I_{1}, I_{2}$ and $I_{3}$ are three different invariant of deformation tensor, which can be defined in terms of principal stretch ratio $\lambda_{1}, \lambda_{2}$ and $\lambda_{3}$ presented by [3]:

$$
\begin{aligned}
& I_{1}=\lambda_{1}^{2}+\lambda_{2}^{2}+\lambda_{3}^{2} \\
& I_{2}=\lambda_{1}^{2} \lambda_{2}^{2}+\lambda_{2}^{2} \lambda_{3}^{2}+\lambda_{3}^{2} \lambda_{1}^{2} \\
& I_{3}=\lambda_{1}^{2} \lambda_{2}^{2} \lambda_{3}^{2}
\end{aligned}
$$

Mostly, hyperelastic materials are considered as incompressible $\left(I_{3}=1\right)$. Hence, $I_{1}$ and $I_{2}$ are the two remaining independent strain measures. This gives us that ' $W$ ' is a function of only $I_{1}$ and $I_{2}[1]$ :

$$
W=W\left(I_{1}-3, I_{2}-3\right)
$$

We can select the suitable strain energy function (SEF) depending on the available data, variables and its application for identifying material parameters. [4]. As [5] described few main qualities of an efficient hyperelastic material, are given below:

- Must have the ability to exactly replicate rubber's "S" shape in response. 
- The parameters of fitting elements should be small, in order to determine them with a smaller number of experimental tests.

- If the model operates with acceptable results in uniaxial tension, it must also be the same for equi-biaxial extension and simple shear.

- Mathematical formulae must be simple for implementing the numerical parameters of the model.

To achieve better precise results and prediction in an assembly, by Finite Element Simulation (FES), model should be tested under the same force/loading conditions as the real-life assembly [6]. Uniaxial tests are well understandable and very easy to perform [7] but only uniaxial data is not enough to give us reliable coefficients of the model. [8]. Specially if the original model experiences complex state of stresses.

\section{Tensile test and Standards}

Following test procedures used to evaluate the tensile properties of thermo-plastic elastomers and vulcanized rubbers.

Method A: Dumbell with straight section specimen

Method B: Ring specimen

We would be testing with method A. Testing parameters and standard provided for rubber tensile tests falls under ASTM D412. The determination of tensile properties begins with test specimens taken from the sample rubber, including the preparation of the test specimens and the testing of specimens. Test pieces (speciemens) will be in the shape of dumbbells with uniform cross-sectional area [9]. Measurements for tensile strength, tensile stress, tensile stress at given elongation, ultimate elongation and yield point are made on specimen that have not been pre-stressed. Yield point, tensile stress and tensile strength are based on the actual cross-sectional area of a uniform cross section of the specimen.

\subsection{Use and Significance}

All products and materials covered by these test methods must withstand tensile forces for adequate performance for certain applications. These test methods allows us for the measurement of tensile properties [10]. However, tensile properties alone might not directly give the total end use required performance of the material because of the wide range of performance requirement in actual use.

Tensile properties depend on both parameters, the condition of test (temperature, specimen geometry, extension rate, humidity, temperature, etc.) and the material; therefore, material should be tested and compared only when they are tested under the same conditions. [11]

Rate of extension and temperature may have significant effects on tensile properties and therefore these parameters should be controlled. These effects may vary depending on the type of material or product being tested. 
Tensile set gives us the residual deformation which is partly recoverable and partly permanent after retraction and stretching. For such results and behaviour, the periods of recovery and extension must be controlled to obtain considerable and comparable results.

\subsection{Apparatus}

1. Testing Machine - Tension tests should be made on a power-driven machine which is equipped to produce a uniform speed, rate of grip separation / speed of $500 \pm 50 \mathrm{~mm} / \mathrm{min}$ with a distance of at least $750 \mathrm{~mm}$. The testing machine should have a suitable dynamometer and a recording or an indicating system for measuring the applied force. If the capacity range of the machine cannot be changed for the tests (such as pendulum dynamometers) the applied force at break should be measured within $62 \%$ of the full-scale test value and the smallest tensile force measured should be accurate within $10 \%$.

The response of the recorder should be quick enough so that the applied force is measured with the required accuracy during the extension of the specimen to break or tear off. If the machine is not equipped with a proper recorder, another device should be attached that can indicate the maximum stress applied during extension and after fupture. Testing machines should be capable of measuring the elongation of the test specimen with minimum increments of $10 \%$.

Test Chamber for Low Temperatures and Elevations should conform with the below requirements:

I. Acting grips suitable for adjustment and manipulation at low or high temperatures may be installed and provided to allow the placement of specimens in the grips under the shortest time possible to minimize any fluctuation in the temperature of the chamber.

II. Air should be circulated through the chamber at a velocity of 1 to $2 \mathrm{~m} / \mathrm{s}$ at the spindles or grips and test piece maintained within $2^{\circ} \mathrm{C}$ of earlier specified temperature.

III. Provisions should be made for suspending specimens vertically near the grips or spindles for conditioning in the beginning of the test. The specimens shouldn't touch each other or the sides of the chamber.

IV. A calibrated temperature sensor should be located and installed near the spindles or grips to measure the actual temperature.

V. The chamber should have an exhaust system to remove any fumes that liberate at high temperatures.

VI. The dynamometer should be suitable for the temperature of the test being carried out or it should be insulated thermally from the chamber.

VII. Preperation should be made for measuring the elongation of specimen in the chamber. If a scale is used to measure the extension between the benchmarks then the scale should be located close and parallel to the gripping hand during specimen's extension and should be controlled from outside the chamber. 


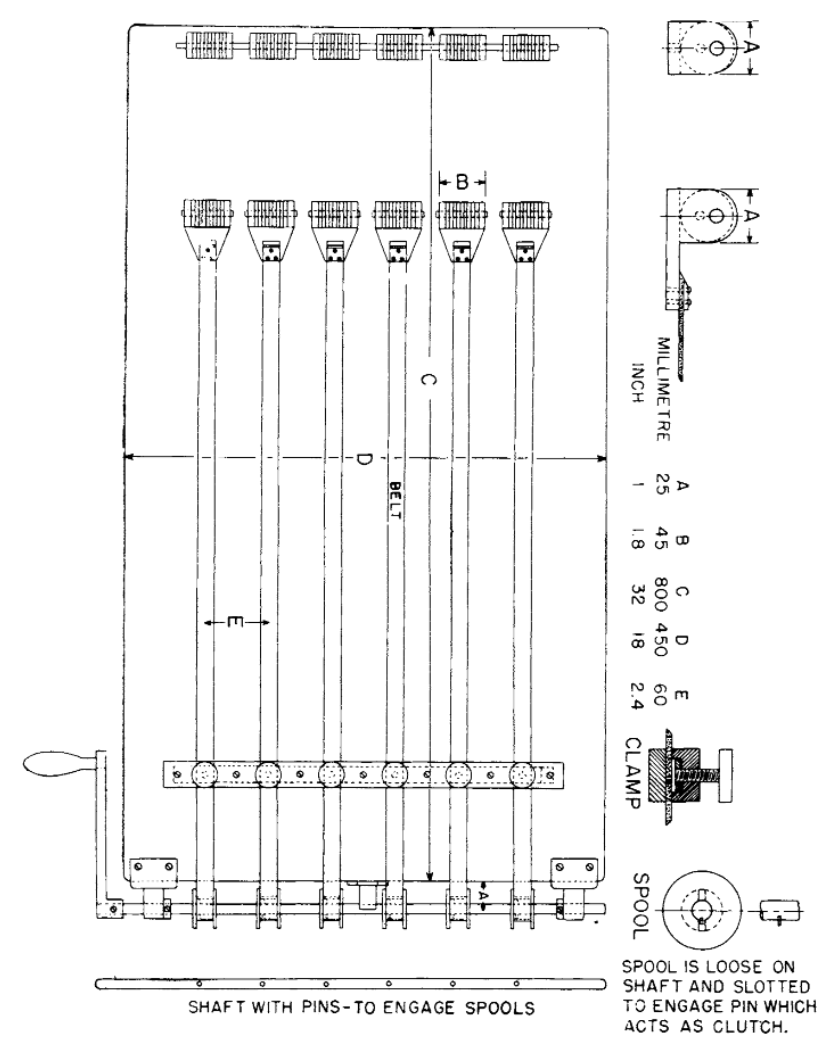

Figure 1. Apparatus of Tensile Test

2. The testing machine described in point 1 or an apparatus similar to that shown in Fig. 1 [12] can be used. A stop watch should be used for measuring in minute intervals for at least 30 minutes. A scale or other device shall be provided for measuring tensile set to within $1 \%$.

\section{Principles of FEA}

The Finite Element Method (FEM) or Finite Element Analysis (FEA), is a computerized based technique that is used to acquire estimated solutions regarding boundary value issues in engineering. Boundary value problems are also termed as field problems. The field most frequently characterizes a physical structure and is the area of interest [13]. The field variables are dependent variables of interest administered by differential equation. The boundary circumstances are the particular values of the field variables or related variables, such as derivatives, on the boundaries of the field. [14]

For finite element analysis, hyper elasticity theory represents non-linear behavior of hyper elastic material at large forces. Usually stress-strain curve data is taken from the experiments and is used to find constants of theoretical models to fit the material behavior. There are many hyper elasticity theories available, some of which are shown below,

\subsection{Mooney-Rivlin Model}

Two parameters phenomeno-logical model that works properly for quite large stains for shear deformation and uniaxial elongation [15] [16]. But it cannot seize the peak (S-curvature) of the force 
extension relation in uniaxial test and the force shear displacement relation in shear test. For a compressible rubber, model is shown below,

$$
W=C_{10}\left(\overline{I_{1}}-3\right)+C_{10}\left(\overline{I_{2}}-3\right)+\frac{1}{D_{1}}\left(J_{e l}-1\right)^{2}
$$

\subsection{Neo-Hookean Model}

This is a special case of Mooney-Rivilin form with $\mathrm{C}_{01}=0$ and can be used when we have insufficient material data. It can make good approximation and is simple to use at small strains. But also, it cannot seize the peak upturn of stress-strain curve.

$$
W=C_{10}\left(\overline{I_{1}}-3\right)+\frac{1}{D_{1}}\left(U_{e l}-1\right)^{2}
$$

\subsection{Yeoh Model}

Yeoh [17] proposed in 1993 a phenomenological model in third order form polynomial based on only $I_{1}$ first invariant. This model can be used for characterization of rubbed filled with carbon-black and it also can capture the peak upturn of stress-strain curve. It is good for large strain range and with limited data, it can simulate many modes of deformation. This leads us to reduce the requirements for testing a material [18]. It is also known as the reduced polynomial model and it can be given as:

$$
W=\sum_{i=1}^{3} C_{i 0}\left(\bar{I}_{1}-3\right)^{i}+\sum_{i=1}^{3} \frac{1}{D_{i}}\left(J_{e l}-1\right)^{2 i}
$$

\subsection{Ogden Model}

This model was proposed in 1972 by ogden [19] [20], it is based uppon principa; stretches rather than invariants. It can capturn the upturn of stress-strain curve and rubber models precisely for large deformations. This model shouldn't be used with limited tests like just uniaxial test.

$$
W=\sum_{i=1}^{N} \frac{2 \mu_{i}}{a_{i}^{2}}\left(\lambda_{1}^{-a_{i}}+\lambda_{2}^{-a_{i}}+\lambda_{3}^{-a_{i}}-3\right)+\sum_{i=1}^{N} \frac{1}{D_{i}}\left(J_{e l}-1\right)^{2 i}
$$

\section{References}

[1] A. Gent, Engineering with rubber: how to design rubber components. 2nd ed., Munich: Hanser Gardener Publication, 2000.

[2] Ali, M. Hosseini and B. Sahari, A review of constitutive models for rubber-like materials., American Journal of Engineering and Applied Sciences, 2010. 
[3] D. P. P, J. Limtragool, S. Inban and S. Piyasin, Hyperelastic Material Models for Finite Element Analysis with Commercial Rubber, Khon Kaen, Thailand: echnology and Innovation for Sustainable Development Conference (TISD2006), 2006.

[4] H. A. K. Khajehsaeid and R. Naghdabadi, A hyperelastic constitutive model for rubber-like materials., European Journal of Mechanics., 2013.

[5] G. Chagnon, G. Marckmann and E. Verron, A comparison of the Hart-Smith model with Arruda-Boyce and Gent formulations for rubber elasticity., Rubber Chemistry and Technology., 2004.

[6] D. Huri, "Finite Element Software for Rubber Products Design," INTERNATIONAL JOURNAL OF ENGINEERING AND MANAGEMENT SCIENCES / MÚSZAKI ÉS MENEDZSMENT TUDOMÁNYI KÖZLEMÉNYEK, pp. 13-20, 2018.

[7] B. Duncan, A. Maxwell, L. Crocker and R. Hunt, Verification of hyperelastic test methods. Teddington: NPL, NPL Report CMMT(A) 226., 1999.

[8] M. P. G. Sasso, G. Chiappini and D. Amodio, Characterization of hyperelastic rubber-like materials by biaxial and uniaxial stretching tests based on optical methods., Polymer Testing; 27(8):995-1004., 2008.

[9] D. Huri, "Incompressibility and mesh sensitivity analysis in finite element simulation of rubbers," INTERNATIONAL REVIEW OF APPLIED SCIENCES AND ENGINEERING, pp. 7-12, 2016.

[10] M. Tamás, H. Dávid, K. Imre, K. Imre and S. Tamás, "Material Characterization and Numerical Simulation of a Rubber Bumper," INTERNATIONAL JOURNAL OF MECHANICAL AEROSPACE INDUSTRIAL MECHATRONIC AND MANUFACTURING ENGINEERING, pp. 1367-1370, 2014.

[11] T. Mankovits, T. Szabó, I. Kocsis and I. Páczelt, “Optimization of the Shape of Axi-Symmetric Rubber Bumpers," STROJNISKI VESTNIK-JOURNAL OF MECHANICAL ENGINEERING, pp. 61-71, 2014.

[12] A. international, "Standard Test Methods for Vulcanized Rubber and Thermoplastic Elastomers," in astdm-d412, 2008.

[13] D. Huri and T. Mankovits, "Automotive rubber part design using machine learning," IOP CONFERENCE SERIES: MATERIALS SCIENCE AND ENGINEERING, pp. 1-6, 2019.

[14] H. Dávid and M. Tamás, "Comparison of the material models in rubber finite element analysis," IOP CONFERENCE SERIES: MATERIALS SCIENCE AND ENGINEERING, p. 393, 2018.

[15] M. MA, “A theory of large elastic deformation.," in Journal of Applied Physics., 1940.

[16] R. RS, "Philosophical Transitions of the Royal Society of London," in Large elastic deformations of isotropic materials I: fundamental concepts, london, 1948, pp. 459-490.

[17] Y. OH, “Some form of strain energy functions for rubber. Rubber Chemistry and Technology.," 1993.

[18] Renaud, J. Cros, Z. Feng and B. Yang, "The Yeoh model applied to the modeling of large deformation contact/impact problems.," International Journal of Impact Engineering., 2009. 
International Journal of Engineering and Management Sciences (IJEMS) Vol. 5. (2020). No. 2 DOI: 10.21791/IJEMS.2020.2.2.

[19] R. Ogden, "Large deformation isotropic elasticity - on the correlation of theory and experiment for the incompressiblerubber-like solids.," Proceedings of the Royal Society of London. Series A, Mathematical and Physical Sciences. , pp. 565-584, 1972.

[20] R. Ogden, "Large deformation isotropic elasticity—on the correlation of theory and experiment for the compressible rubberlike solids.," Proceedings of the Royal Societyof London A., pp. 567-583, 1972. 